\title{
Brain Aging: Changes in the Nature of Information Coding by the Hippocampus
}

\author{
Heikki Tanila, ${ }^{1}$ Matthew Shapiro, ${ }^{2}$ Michela Gallagher, ${ }^{3}$ and Howard Eichenbaum ${ }^{4}$ \\ ${ }^{1}$ Department of Neuroscience and Neurology, University of Kuopio, 70211 Kuopio, Finland, 2 Department of Psychology, \\ McGill University, Montreal, Quebec QC H3A 1B1, Canada, ${ }^{3}$ Department of Psychology, University of North Carolina at \\ Chapel Hill, Chapel Hill, North Carolina 27599, and ${ }^{4}$ Department of Psychology, Boston University, Boston, \\ Massachusetts 02215
}

\begin{abstract}
Advanced age in rats is associated with a decline in spatial memory capacities dependent on hippocampal processing. As yet, however, little is known about the nature of age-related alterations in the information encoded by the hippocampus. Young rats and aged rats identified as intact or impaired in spatial learning capacity were trained on a radial arm maze task, and then multiple parameters of the environmental cues were manipulated to characterize the changes in firing patterns of hippocampal neurons corresponding to the presence of particular cues or the spatial relationships among them. The scope of information encoded by the hippocampus was reduced in memory-impaired aged subjects, even though the
\end{abstract}

number of neurons responsive to salient environmental cues was not different from that in young rats. Furthermore, after repeated manipulations of the cues, memory-intact aged rats, like young rats, altered their spatial representations, whereas memory-impaired aged rats showed reduced plasticity of their representation throughout testing. Thus changes in hippocampal memory representation associated with aging and memory loss can be characterized as a rigid encoding of only part of the available information.

Key words: spatial learning; spatial memory; place field; electrophysiology; encoding; representation; rat; age
Diminished memory capacity is a well known concomitant of aging in humans (Craik, 1990; Rapp and Heindel, 1994) and animals (Barnes, 1980, 1988; DeToledo-Morrell et al., 1988; Gage et al., 1988; Rapp and Amaral, 1992; Rapp and Heindel, 1994; Gallagher et al., 1995). Across all species studies have found that the memory deficit associated with aging is characterized by large variability in cognitive capacities so that some aged subjects perform as well young subjects, whereas others show severe impairment (Markowska et al., 1989; Bachevalier et al., 1991; Rapp and Amaral, 1992; Gallagher et al., 1993). Many experiments have identified anatomical, molecular, and physiological markers of memory impairment in the hippocampal region of aged animals and humans (Barnes, 1979, 1988; DeToledo-Morrell et al., 1988; Gage et al., 1988; Rapp and Amaral, 1992; Gallagher et al., 1994; Rapp and Heindel, 1994; Grady et al., 1995; Rapp and Gallagher, 1996), but few studies to date have characterized age-associated changes in the nature of information encoded by neurons in the brain.

In rats aging results in an impairment in spatial learning and memory. Spatial learning in rats is strongly dependent on hippocampal function (Morris et al., 1982), and the firing patterns of hippocampal pyramidal cells correlate with the spatial location of an animal in the testing environment during exploratory behavior

Received Feb. 10, 1997; revised April 9, 1997; accepted April 11, 1997.

This work was supported by the National Institute on Aging, National Institute of Mental Health, Academy of Finland, Medical Research Council of Canada, National Science and Engineering Research Council of Canada, and McGill University for salary support of M.S. during his sabbatical. Thanks to J. Niedermair for preparation of histological material for confirmation of electrode locations and Dr. C. Barnes for critical comments on this manuscript.

Correspondence should be addressed to Dr. Howard Eichenbaum, Laboratory of Cognitive Neurobiology, Department of Psychology, Boston University, 64 Cummington Street, Boston, MA 02215.

Copyright (C) 1997 Society for Neuroscience $0270-6474 / 97 / 175155-12 \$ 05.00 / 0$
(O'Keefe and Nadel, 1978). The firing pattern of such hippocampal "place cells" is controlled by spatial and other relationships among multiple environmental cues and ongoing behavior and may reflect higher-order memory processing (O'Keefe and Nadel, 1978; Muller and Kubie, 1987; Eichenbaum, 1996).

The activity of place cells in rats exploring a maze can be influenced by both distal (extramaze) and local (intramaze) cues (Young et al., 1994). Furthermore, aged rats can succeed as well as young rats in maze learning when performance is guided by specific intramaze cues (Barnes et al., 1987), suggesting that hippocampal processing of intramaze cues is intact in aged animals. In addition, rats with fimbria-fornix lesions switch from using extramaze cues to intramaze cues when both are available to solve a radial arm maze task (M'Harzi and Jarrard, 1992), and hippocampal place cells in fornix-damaged rats are controlled by intramaze cues (Shapiro et al., 1989). These findings suggest that compromise in hippocampal function, including aging, results in changes in the firing patterns of hippocampal neurons characterized by a reduction in the control by spatial relations among distal extramaze cues and corresponding increases in control by single cues and local intramaze stimuli. In addition, one might expect hippocampal neurons of aged rats to be less likely to develop any spatial firing correlate; that is, there might be fewer place cells in the aged hippocampus. The present study focused on the possibility that age results in alterations of the nature of environmental cues encoded by the hippocampus and on the plastic alterations in information coding when the spatial cues are manipulated.

\section{MATERIALS AND METHODS}

Subjects. Seven young (4-6 months, 350-450 gm, at the beginning of the recordings) and seven aged (25-29 months, 450-600 gm) male LongEvans rats served as subjects. All rats were received at 3-4 months of age as retired breeders and were individually housed in large cages through- 
out the experiment. During the entire experiment all rats were maintained on a $12 \mathrm{hr}$ light/dark cycle and given ad libitum access to water. Access to food was controlled to prevent weight increase during the experiment. The health of the aged rats was followed by monitoring their food and water consumption and general health. When the brains of the rats were removed for histological verification of the electrode marks, all brains were carefully inspected for tumors. One of the aged rats had a noninfiltrating cerebellar tumor. Because the place fields and behavior of this rat did not differ from the others, the rat was included in the study. The aged rats were prescreened for performance in the Morris water maze task at the University of North Carolina at Chapel Hill and then transported to the State University of New York at Stony Brook (Stony Brook, NY) for the recording studies. Three of the aged rats had spatial learning scores within the performance range of young adult rats (Gallagher et al., 1993) and were therefore considered memory-intact. Four of the aged rats had learning indices outside the range of young rats and were therefore considered memory-impaired. The experimenter conducting the recordings was blind to the learning indices of the aged rats.

Electrodes and surgery. The recording electrode consisted of a twisted bundle of four $30 \mu \mathrm{m}$ Formvar-coated nichrome wires of equal length (a tetrode) plus two single wires cut 200-500 $\mu \mathrm{m}$ shorter that served as indifferent electrodes. The electrode bundle was strengthened with super glue and inserted into a 29 gauge cannula. The cannula was attached to a custom microdrive with a connector (Hetherington and Shapiro, 1996). The stimulating electrode consisted of a twisted pair of Formvar-coated $100 \mu \mathrm{m}$ stainless steel wires that differed in length by $300-500 \mu \mathrm{m}$.

The animals were anesthetized with ketamine $(50 \mathrm{mg} / \mathrm{kg})$ and xylazine $(7.5 \mathrm{mg} / \mathrm{kg}$, i.m.) and supplemented with ketamine $(20 \mathrm{mg} / \mathrm{kg})$ when necessary. Stimulation electrodes aimed for the lateral hypothalamus were implanted at $0.5 \mathrm{~mm}$ posterior and 1.5 lateral to bregma and $7.7 \mathrm{~mm}$ below the pial surface (tip of the longer wire). The tetrode aimed at dorsal CA1 was implanted at $3.3 \mathrm{~mm}$ posterior and 2.0 lateral to bregma and $1.5-1.9 \mathrm{~mm}$ below the pial surface. The microdrive and the connector were attached to the surface of the skull by dental cement and four stainless steel screws, two of which also served as the electrical ground.

Unit recording and data acquisition. Seven to $10 \mathrm{~d}$ after surgery rats were screened once or twice daily for unit activity. If no pyramidal cell activity was identified, the tetrode was advanced $40-80 \mu \mathrm{m}$. After each recording session the electrode was advanced $80 \mu \mathrm{m}$ and allowed to settle at least $24 \mathrm{hr}$ to ensure that the same units would not be recorded repeatedly. Only complex spike cells (Ranck, 1973) with a duration of the negative spike of more than $300 \mu \mathrm{sec}$ and a signal-to-noise ratio of more than $3: 1$ were sampled for this study. Neural activity was first passed through a source follower on the rat's head stage and then differentially amplified (5000-10,000 times) by an AC amplifier (AM-Systems Inc.) and then bandpass filtered $(0.3-5 \mathrm{kHz})$ and digitized $(25 \mathrm{kHz}$, Data Translation DT2821) using an IBM compatible 486-based personal computer and Enhanced Discovery software (DataWave Technologies Inc.). Unit isolation was initially achieved on-line using the Spike Sort module of the Enhanced Discovery software and then confirmed or redefined off-line using Autocut software (DataWave Technologies). Most units were recorded with the tetrodes, but occasionally the indifferent wires also yielded units with a high signal-to-noise ratio, fulfilling the criteria for complex spike neurons, and were included in the study. In both cases, units were isolated by identifying clusters defined by waveform parameters (McNaughton et al., 1989). The recordings were considered stable if the clusters remained within the same fixed boundaries throughout the experiment (Fig. 1).

The position of the rat in the maze was determined by a video camera following system (DataWave Technologies) that tracked two incandescent light bulbs mounted on the head stage assembly. One of the light bulbs was bright, and the other was dim, and they were separated by $6 \mathrm{~cm}$. The location was digitized in the form or $x$ - and $y$-coordinate pairs at the rate of $60 \mathrm{~Hz}$ by an analog-to-digital converter in the data acquisition system.

Behavioral apparatus. The apparatus consisted of a four-arm radial maze elevated $70 \mathrm{~cm}$ above the floor (Fig. 2). The maze had a central octagonal platform $12 \mathrm{~cm}$ on each side and four maze arms, each of which was $45 \mathrm{~cm}$ long, $10 \mathrm{~cm}$ wide, and had $6 \mathrm{~cm}$ angled sides at the end of each arm. The apparatus was surrounded by four $175-\mathrm{cm}$-wide dark blue curtains, each of which supported a distinct 30- to 90 -cm-wide, complex contrasting pattern that served as a distal cue. The local cues were surfaces that overlaid the maze arms and were composed of coarse plastic mesh, sandpaper, fine wire mesh, or coarsely ridged rubber. In addition, each arm was sprayed daily with an aerosol of a common food odor

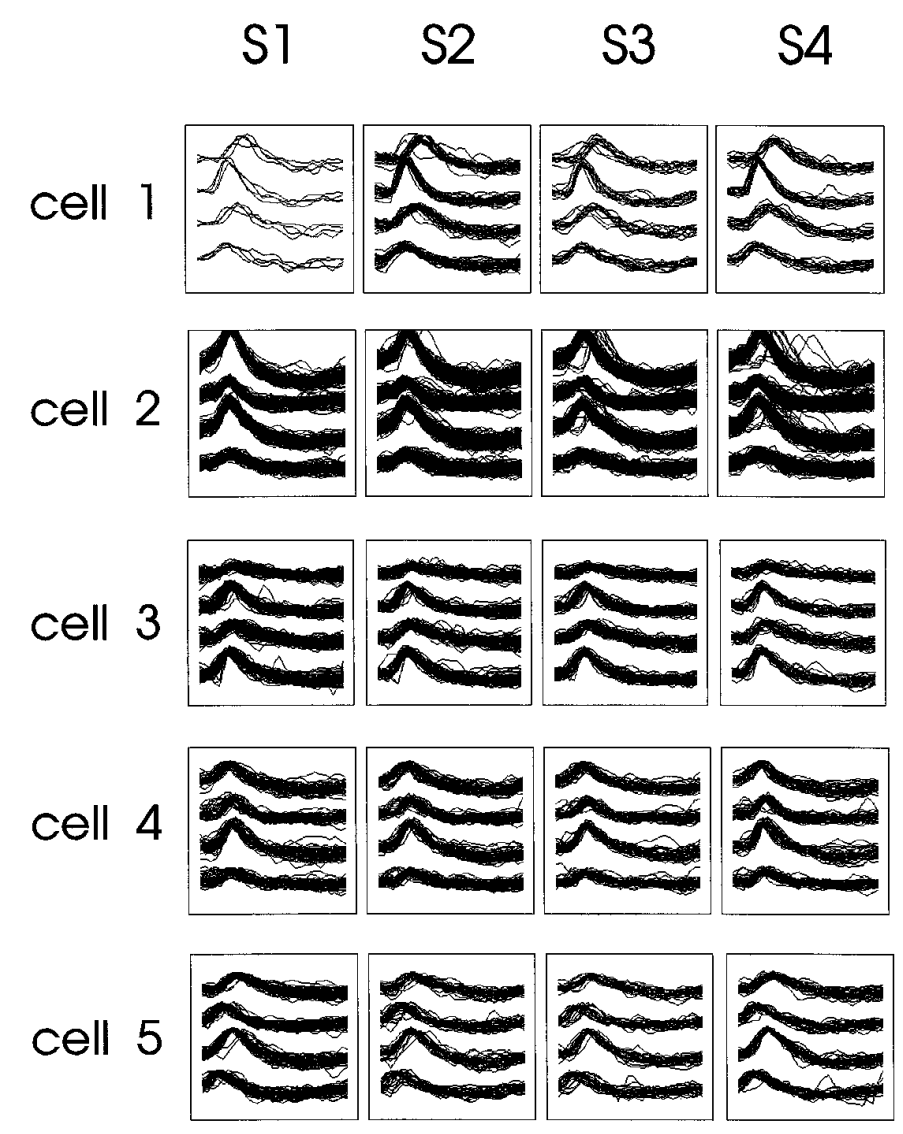

Figure 1. An example of the stability of cell isolation for a single recording session. Shown are the tetrode waveforms for five different cells (cell 1-cell 5) of a memory-impaired aged rat recorded during four standard conditions (S1-S4). Each set of overlapping waveforms represents sample traces from one of the tetrode wires.

(anise, coconut, strawberry, or peppermint). The maze was illuminated by four $12 \mathrm{~V} \mathrm{DC}$ lights located symmetrically on a ceiling panel above the maze. White noise was delivered by two speakers on the ceiling panel. The curtained enclosure could be entered from either of two opposite corners.

Behavioral procedures. Although the tetrode was slowly moved toward CA1 over 1-2 weeks, the rats were trained to visit the ends of the arms and to return to the center by rewarding them with electrical stimulation to the lateral hypothalamus $(0.5$ trains/sec of $0.5 \mathrm{msec}$ pulses at $100 \mathrm{~Hz}$, $60-200 \mu \mathrm{A})$. The stimulus current was adjusted to the minimal level that kept the rat constantly moving. When this was achieved a working memory contingency was introduced such that rats received rewarding stimulation only when they ran to the end of an arm not previously visited on that trial. When all four arms had been visited, a new trial began immediately. All the rats adopted a stereotypic movement pattern that involved runs into adjacent arms, occasionally changing the direction of rotation among runs within a recording condition. As evident in the stereotypic arm choice pattern, the rats may not have used spatial memory to solve the task.

During recording sessions place fields of the isolated cells were first mapped with all the cues in the arrangement used during training; these are referred to below as the standard condition. Subsequently the presence and relative positions of distal and local cues were manipulated in probe trials (test conditions) to determine which stimuli controlled place cell activity. Data were collected continuously over 5-10 min for each condition (which contained 8-16 trials), and the rat was placed in a round, covered bucket between conditions. Before a new condition the bucket was gently spun (four one-fourth to one-half turns to opposite directions) to disorient the rat. In addition, the start arm was alternated pseudorandomly, and the experimenter used two opposite corners to enter and leave the enclosure.

Five types of cue manipulations were used in test conditions that 


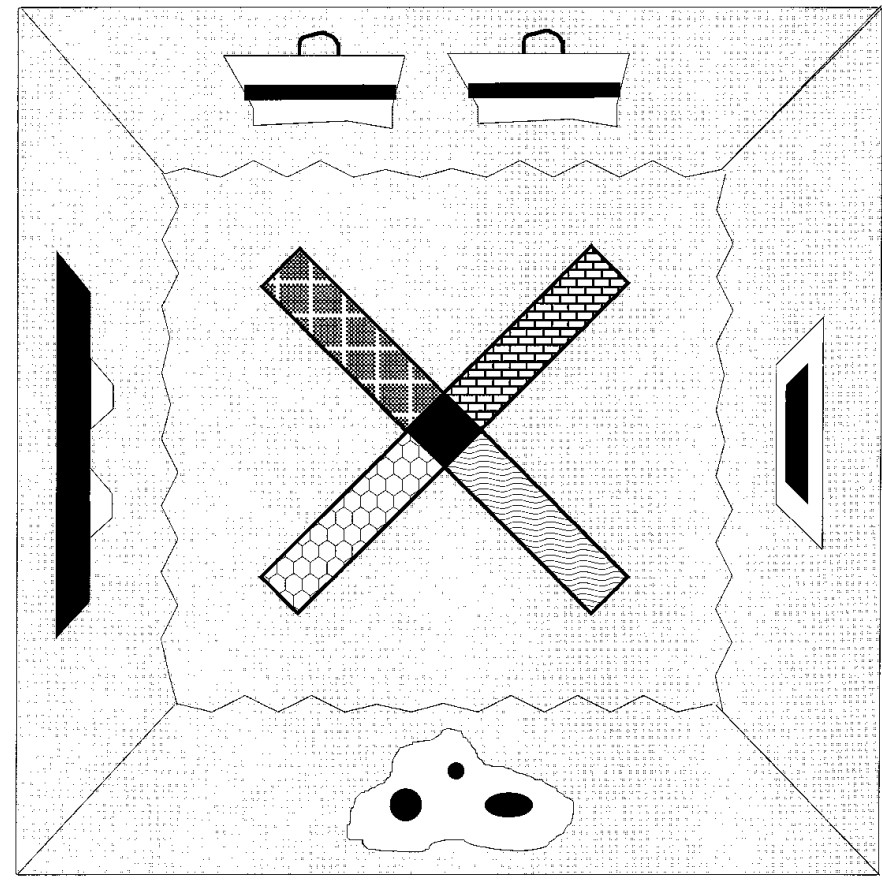

Figure 2. Schematic diagram of a top view of the radial maze showing distal cues on the walls surrounding the maze and local cues on the maze arms.

alternated with the standard condition: (1) in the double rotation condition all the distal cues were rotated $90^{\circ}$ clockwise, and all the local cues were rotated $90^{\circ}$ counterclockwise, or vice versa; (2) in the local scramble condition some or all of the local cues were exchanged randomly to disrupt their standard configuration; (3) in the distal scramble condition some or all of the distal cues were exchanged randomly to disrupt their standard configuration, and the local cues were rotated to determine whether the place field would subsequently become under the control of local or constant room cues; (4) in the local removal condition a single cue closest to the place field was eliminated, and a nontextured, nonodorous maze arm was used as a replacement; and (5) in the distal removal condition the distal cues near the arm with the place field were removed one at a time. A daily session thus consisted of several repetitions of the standard condition that alternated with the five test conditions.

Histology. The nichrome electrodes contained 10\% iron. At the end of the recordings the rats was deeply anesthetized with pentobarbital (60 $\mathrm{mg} / \mathrm{kg}$, i.p.). The electrode tips were marked by passing $15 \mu \mathrm{A}$ anodal current for $10 \mathrm{sec}$ to deposit iron into the tissue. The rat was perfused with saline followed by $4 \%$ formalin, $4 \%$ potassium ferrocyanide, and $4 \%$ glacial acetic acid. The brains were removed, carefully inspected for any gross pathology, and soaked in formalin followed by $30 \%$ sucrose. Standard $30 \mu \mathrm{m}$ frozen sections were cut, and the slices were stained with cresyl violet. The location of electrode tips were identified by the Prussian blue reaction, and the recording sites were determined by estimating distances along the electrode track associated with the microelectrode position at the time of the recording.

Data analysis. For each condition the spatial distribution of firing rates was calculated by dividing the maze into $3 \times 3 \mathrm{~cm}$ pixels and computing the firing rate for each pixel as the total number of spikes divided by the total time spent in that pixel. Firing rates were calculated only for periods when the rat was moving at least $2 \mathrm{~cm} / \mathrm{sec}$. A place field was defined as an area of at least three adjacent pixels each having a firing rate at least three times the grand mean rate (total number of spikes/total time spent moving in the maze) and a mean within-field (infield) firing rate at least five times the overall mean firing rate for that neuron.

The following place field parameters were calculated only for tetrodeisolated cells during the first standard condition for each daily recording session: number of fields, mean infield firing rate, mean place field area (in pixels), directional tuning, and spatial selectivity. To obtain a directional tuning score for a place field, firing rates were calculated separately for the rat's horizontal movement in eight directions. Directional tuning was calculated as the ratio of the maximum and minimum firing rates across all directions of movement observed at least once. Spatial selectivity was calculated as the $\log _{10}$ of the ratio of the mean infield firing rate and the mean firing rate outside the place field (outfield rate). In cases of three or fewer multiple fields the infield/outfield ratio was calculated as follows: infield rate $=$ mean of mean rates for the place fields/combined area of all place fields; outfield rate $=$ outfield volume/outfield area $=$ (total volume - infield volume)/(total area - combined place field area), where infield volume $=$ infield rate $\times$ combined place field area, and total volume $=$ grand mean rate $\times$ total area visited. Some cells had very low outfield firing rates, so a cutoff for spatial selectivity was set to 5000 (and the corresponding $\log _{10}$ was set to 3.70 ).

For all recordings the following parameters were calculated. For the first two standard conditions the spatial reliability of each place field was calculated as the number of visits to the place field with the neuron firing divided by total number of visits to the place field. When there was more than one place field for a cell, the spatial reliability of the neuron was calculated as the average reliability for each of its place fields. Spatial stability was calculated by first resetting the pixel size to $10.5 \times 10.5 \mathrm{~cm}$ and then computing the pixel-by-pixel cross-correlation of firing rates among three standard conditions. Firing onset delay was calculated as the number of runs to each of the arms before a run in which the neuron fires, averaged over the first two standard conditions plus the double rotation condition.

Unit responses to manipulations of the environmental stimuli were assessed by comparing the intensity and location of each place field with the preceding standard condition. The place field was considered fixed if a place field appeared in the same arm with an axial shift less than one-fourth of the arm length. The place field was considered rotated if a place field appeared in a different arm with an axial shift less than one-fourth of the arm length. New place fields were identified as firing meeting the criteria of a place field but not localized within the preceding constraints. The place field was considered to have disappeared if no field could be found in the original or rotated location. Using these criteria, four different overall types of responses to cue manipulations were scored: (1) no change if the place field was fixed, (2) rotation with distal cues if the location of the place field corresponded to the new location of one or more distal cues, (3) rotation with local cues if the location of place field corresponds to the new location of one or more local cues, and (4) new representation if the place field disappeared or any new place fields appeared in a location that did not correspond to the positions of fixed, distal, or local cues; in situations in which multiple responses were observed, this category superseded all the others. When the activity of a place cell totally ceased in a test condition, it usually returned in the following standard condition. If the activity of the cell could not be detected in any of the following conditions of the session, the cell was regarded as lost, and the disappearance of the field was not counted as a response. Furthermore, it was determined whether the frequency of these four responses in place fields changed across repeated testing sessions. The effect of repetitive daily sessions was analyzed by dividing all sessions into three blocks that had an approximately equal number of cells in each group (block 1, sessions 1-4; block 2, sessions 5-8; and block 3, sessions 9-15) and comparing the proportions of the above-mentioned responses among these blocks.

Statistical comparisons. The data were analyzed using two kinds of comparisons between the experimental groups. In between-cells comparisons, the data from all cells within each experimental group were pooled across subjects. This analysis used the assumption that neuronal firing patterns were sampled independently from the same heterogeneous population in all subjects from a particular group. This approach is optimally sensitive to group differences but carries the risk that aberrant firing properties in one animal with many recorded neurons can bias the characterization of the entire experimental group. In separate betweensubjects comparisons, observations on the neurons recorded in each animal were averaged for each session block (Table 1). This analysis is sensitive to differences between subjects in information coding but carries the risk that subjects with only a few recorded cells can distort the group average. Furthermore, this analysis is far less sensitive to group differences than the between-cells comparison because of the small number of subjects in each group. To gain the advantages of both methods of analysis and to balance the risks, the results are presented using both approaches.

The between-cells and between-subjects comparisons for all basic firing properties were performed with ANOVA using subject group, hippocam- 
Table 1. Comparison between cells

\begin{tabular}{lcccl} 
& \multicolumn{2}{c}{ Group means } & \\
\cline { 2 - 4 } Field parameter & Young & $\begin{array}{l}\text { Aged } \\
\text { memory- } \\
\text { intact }\end{array}$ & $\begin{array}{l}\text { Aged } \\
\text { memory- } \\
\text { impaired }\end{array}$ & Significance \\
\hline Number of fields & 1.0 & $1.4^{*}$ & $1.4^{*}$ & $p<0.001$ \\
Field area (pixels) & 7.9 & 7.6 & 10.6 & NS \\
Infield rate (spikes/sec) & 3.2 & 3.5 & 3.6 & NS \\
Directional tuning & 15.5 & 13.7 & 21.0 & NS \\
Spatial selectivity $^{a}$ & 1.6 & 2.2 & 2.5 & NS \\
Spatial reliability $^{b}$ & 0.54 & 0.56 & $0.64^{*}$ & $p<0.01$ \\
Spatial stability $^{c}$ & 0.64 & 0.68 & 0.65 & NS \\
Firing onset delay $^{d}$ & 2.6 & 2.5 & $1.9^{*}$ & $p<0.001$
\end{tabular}

$\overline{{ }^{a} \log 10 \text { of infield/outfield firing rate ratio, e.g., a score of } 2.0 \text { reflects a 100:1 spatial }}$ selectivity.

${ }^{b}$ Probability of firing when rat visits the place field.

${ }^{c} r$ for the cross-correlation between standard episodes.

${ }^{d}$ Number of trials completed before firing appears.

* Significantly different from young control, $p<0.05$, Duncan's test.

pal cell layer (CA1 or CA3), and session block as main factors. Because the effect of cell layer was not significant for any parameters, the data from CA1 and CA3 were pooled for all subsequent tests. Whenever the ANOVA yielded significant effects of the group or session block, a post hoc analysis was performed using Duncan's test with the significance level set to $p<0.05$. In addition, firing onset delays were also assessed by calculating the delay separately for each place field and dividing the scores into three latency categories, allowing us to compare group differences in the numbers of place fields that began firing at different times. This between-fields comparison was performed using a $\chi^{2}$ test.

Between-cells comparisons were also performed to determine group differences in the distribution of responses to the cue manipulations. Potential changes in the distribution of responses associated with repeated environmental manipulations among the three session blocks were determined using $\chi^{2}$ tests in separate between-cells comparisons for each experimental group. Between-subjects comparisons of responses to environmental manipulations were made using a repeated measures ANOVA for four different response types using group and session block as factors. If the distribution of responses differed significantly among the groups or between the session blocks, each response type was further analyzed with a one-way ANOVA followed by Duncan's tests to detect differences between each pair of groups.

\section{RESULTS}

Data were collected from 111 complex spike cells (45 CA1 and 66 CA3) from four old rats characterized as impaired in spatial learning ability, 104 cells (64 CA1 and 40 CA3) from three old rats who had performed as well as young rats in spatial learning, and 146 cells (73 CA1 and 73 CA3) from seven young rats. A preliminary description of the firing properties of the cells in the young rats has been compiled in another report (Shapiro et al., 1995). All well isolated neurons in each subject group had spatially localized activity, or place fields, during some phase of testing. Typical place fields and changes in spatial firing patterns corresponding to the environmental manipulations are shown in Figure 3.

\section{Comparison of basic place field parameters}

Basic place field parameters were calculated for standard conditions in the highly familiar environment. These analyses showed only modest alterations associated with aging in the number and quality of place fields, although some place field parameters changed substantially across repeated testing sessions.

Between-cells comparisons (Table 1) revealed that aged rats had a greater number of place fields per complex spike cell during the first standard condition $\left[F_{(2,301)}=9.9 ; p<0.001\right]$. Across groups the number of fields decreased across session blocks $\left[F_{(2,301)}=19.7 ; p<0.001\right]$, but the group $\times$ session interaction was not significant. Field areas did not differ between the groups but decreased significantly across sessions $\left[F_{(2,258)}=12.9 ; p<\right.$ $0.001]$. The memory-impaired aged rats had larger place fields than did the other groups during the first block, but this difference disappeared during the subsequent blocks [for group $\times$ session interaction, $F_{(4,258)}=2.9 ; p<0.05$ ]. Infield rate and directional tuning did not differ between the groups or among sessions. Spatial selectivity did not differ between the groups but increased greatly toward the end of the experiment in all groups $\left[F_{(2,255)}=\right.$ 41.5; $p<0.001$; Figure 4]. Spatial reliability differed between the groups, such that it was highest in memory-impaired aged rats $\left[F_{(2,340)}=6.4 ; p=0.002\right]$ and decreased with sessions $\left[F_{(2,330)}=\right.$ $14.3 ; p<0.001]$. Spatial stability did not differ between the groups or the sessions. Firing onset delay differed significantly between the groups but not between the sessions $\left[F_{(2,340)}=15.8 ; p=\right.$ $0.0001]$, such that memory-impaired aged rats had briefer delays to firing onset than the two other groups. In the between-subjects analysis (Table 2) spatial selectivity $\left[F_{(2,18)}=20.9 ; p<0.001\right]$ and spatial reliability $\left[F_{(2,27)}=3.6 ; p=0.04\right]$ differed among the sessions, and only firing onset delay differed among the groups $\left[F_{(2,33)}=3.8 ; p=0.03\right]$.

The number of trials to firing onset ranged between 1 and 16 (the cutoff) for different place fields. The distribution of firing onset latencies was unimodal in all groups, having its peak at the first trial. To elucidate further the differences between the experimental groups, the firing onset latencies in standard conditions for each place field (some cells had more than one place field) were divided into three groups: (1) short, one trial or less; (2) intermediate, two or three trials; and (3) long, four or more trials. The consequent distribution of firing onset latencies differed significantly between the experimental groups $\left(\chi^{2}=15.9 ; p=\right.$ $0.003)$. The memory-impaired aged rats had more of the shortest and fewer of the longest firing onset latencies (Fig. 5) than did the young $\left(\chi^{2}=15.8 ; p<0.001\right)$ and memory-intact aged rats $\left(\chi^{2}=\right.$ $6.5 ; p<0.05)$.

\section{Responses to environmental manipulations}

In the double rotation condition, small and roughly equivalent proportions of hippocampal cells in young rats had place fields that followed either the distal $(30.6 \%)$ or local $(17.3 \%)$ cues or remained unchanged and associated with the constant room cues (9.6\%; Fig. 6). The remaining predominant proportion of the cells $(42.3 \%)$ developed qualitatively new and different spatial firing patterns such that the place field either moved to a new location inconsistent with the stimulus rotations or disappeared or new place fields appeared, indicating that the hippocampus of young rats predominantly encoded the full configuration of distal and local cues. By contrast, most place fields (76.8\%) of memoryimpaired aged rats rotated strictly with the distal cues. A smaller proportion of cells $(18.3 \%)$ developed a new spatial firing pattern, and almost no cells $(2.8 \%)$ were controlled by local or constant room cues. In aged rats with intact memory the pattern of information coding was intermediate between that of young rats and memory-impaired aged rats for this and other types of test conditions described below (Fig. 6).

A $\chi^{2}$ analysis of the between-cells comparisons revealed a highly significant difference in the distribution of the four response categories among the experimental groups $\left(\chi^{2}=83.4 ; p<\right.$ 0.00001 ) and between each pair of groups (all $p<0.01$ ). The between-subjects comparison using ANOVA revealed a signifi- 


\section{Standard Double rotation}

\section{Distal cue Local Distal removal scramble scramble}

\section{A Maze configurations.}

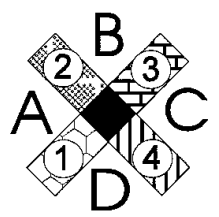

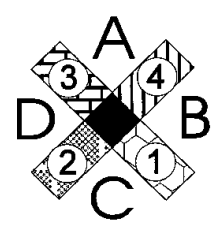

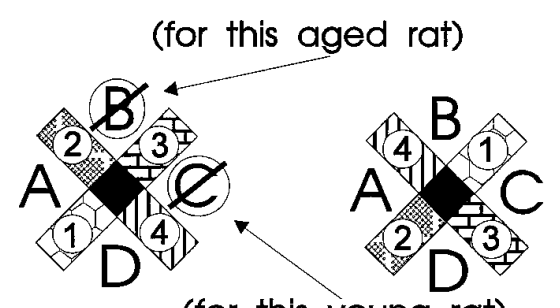

(for this young rat)

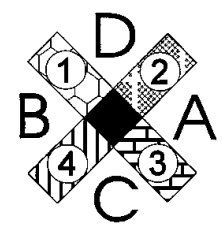

\section{B Place fields in a young rat.}
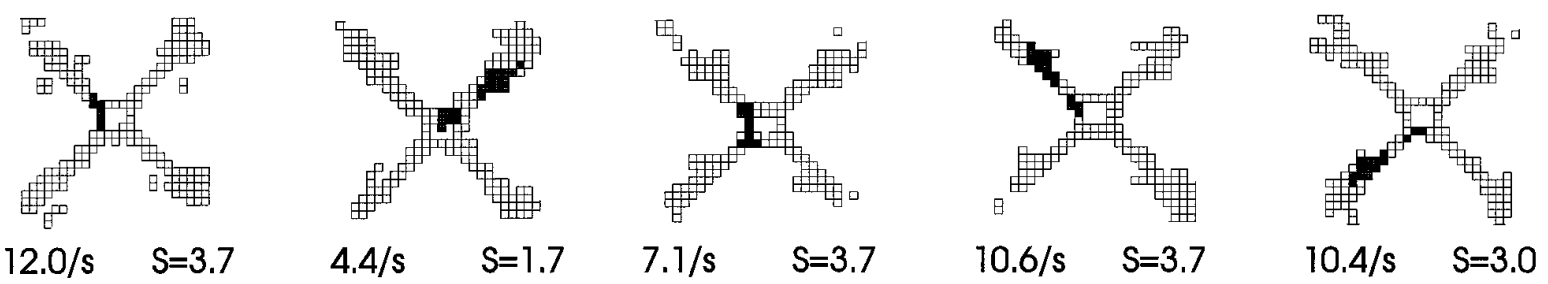

\section{Place field in a memory-impaired aged rat.}
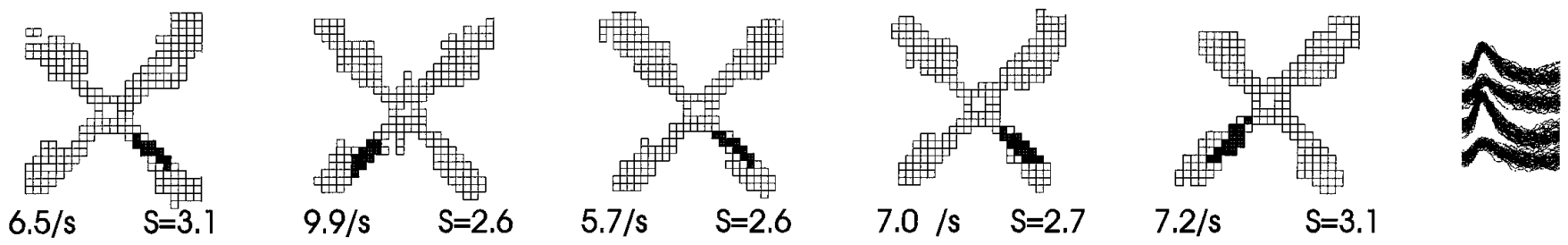

Figure 3. A, Schematic diagrams of the radial maze with the standard configuration of distal and local cues, as well as those for a double rotation condition. The locations of distal cues are indicated by letters, and those of the local cues are portrayed as different patterns on the maze arms. The mean firing rate within the place field and spatial selectivity ratio $(S$, see $B)$ are indicated for each panel. $B$, Spatial firing patterns of a typical hippocampal neuron in a young rat. This cell had a distinct place field in one area during standard conditions and two place fields during the double rotation condition. Gray areas indicate pixel locations outside the place field visited on at least three observations; black areas identify pixels included in the place field(s). $C$, Spatial firing patterns of a typical hippocampal neuron in a memory-impaired aged rat. The place field rotated in correspondence with the distal cues in the double rotation condition. $D$, Overlapping action potential waveforms recorded from across the four tetrode channels for each cell.

cant response type $\times$ group interaction $\left[F_{(6,72)}=6.3 ; p<0.001\right]$. The subsequent one-way ANOVA revealed significant group differences in the number of cells showing no change $\left[F_{(2,30)}=3.6\right.$; $p=0.04]$ and in the number of cells that rotated with the distal cues $\left[F_{(2,30)}=9.0 ; p<0.001\right]$. The memory-impaired aged rats differed significantly from young rats in the number of cells showing no change. Memory-impaired aged rats also differed from both memory-intact aged rats and young rats in the number of cells that rotated with the distal cues (Duncan's tests, $p<0.05$ ).

A closer examination of responses classified as new representations during the double rotation condition revealed other differences among the experimental groups. New representations were divided into three subcategories: (1) disappearance of the place field that was present during the preceding standard condition with no substituting new field (which usually implicated turning off the neuron), (2) rotation with enhancement of an initially weak place field, and (3) appearance of a new field. An example of a place field that disappears in the double rotation is presented in Figure $7 A$. Some place fields that appeared for the first time during the double rotation condition on closer exami- nation are better characterized as a variant of rotation with distal cues. Cells in this subcategory, called rotation with enhancement, were almost silent during the first standard condition but had a constant field in the following standard conditions. Strictly following our protocol that compares the firing patterns after each manipulation with those on the preceding standard condition leads to categorization of these responses as new place fields. However, comparison between double rotation and any of the following standard conditions showed that these fields retain their axial location and only rotate with the distal cues. Moreover, those few spikes that occurred during the first standard condition fell within the same location in which a place field was situated in the following standard conditions (Fig. $7 B$ ). It seemed that minimal firing of those cells apparent during the first standard condition became enhanced during altered configurations of the cues in subsequent test conditions. Alternatively, a place field that appeared during double rotation was classified as a new field if it differed from the field in the standard condition in its axial location in the maze arm by more than one-fourth of the arm length (Fig. $7 C$ ). Sometimes the new place field could be seen 


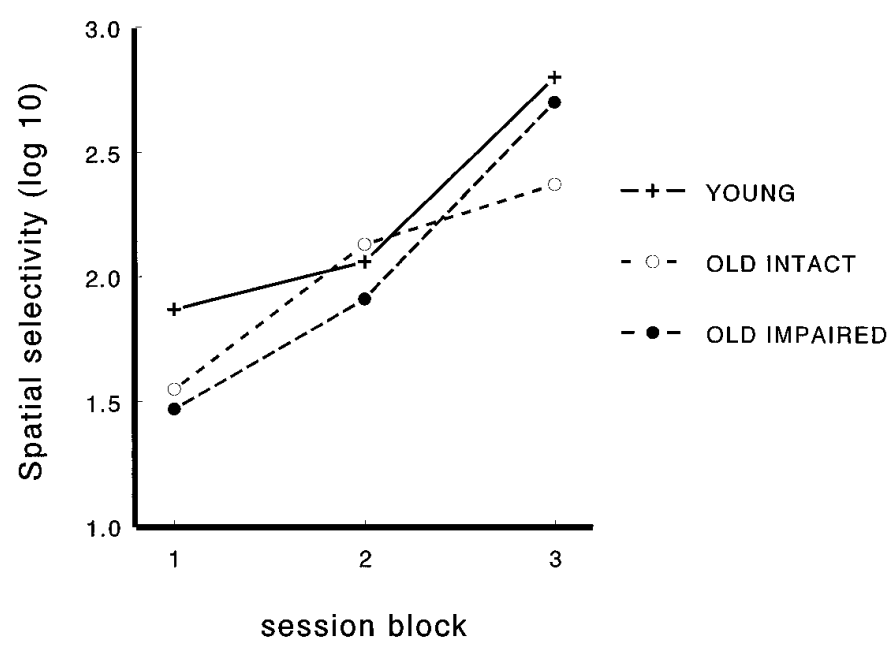

Figure 4. Changes in spatial selectivity over blocks of daily recording sessions. Selectivity is measured as the $\log _{10}$ of the ratio of firing rate inside the place field and the average firing rate outside the place field. Thus, for example, a score of 1 reflects a 10:1 spatial selectivity, and a score of 2 reflects a 100:1 spatial selectivity (session blocks: 1 , sessions 1-4; 2 , sessions 5-8; 3, sessions 9-15). Spatial selectivity increased toward the end of the experiment similarly in all groups.

Table 2. Comparison between subjects

\begin{tabular}{lcccl} 
& \multicolumn{2}{c}{ Group means } & \\
\cline { 2 - 4 } & \multicolumn{3}{c}{$\begin{array}{l}\text { Aged } \\
\text { memory- }\end{array}$} & $\begin{array}{l}\text { Aged } \\
\text { memory- }\end{array}$ \\
Field parameter & Young & intact & Significance \\
\hline Number of fields & 1.3 & 1.5 & 1.4 & NS \\
Field area (pixels) & 8.9 & 7.5 & 11.2 & NS \\
Infield rate (spikes/sec) & 3.6 & 3.5 & 3.7 & NS \\
Directional tuning & 17.9 & 16.6 & 23.1 & NS \\
Spatial selectivity $^{a}$ & 1.7 & 2.1 & 2.6 & NS \\
Spatial reliability $^{b}$ & 0.51 & 0.53 & 0.60 & NS \\
Spatial stability $^{c}$ & 0.64 & 0.65 & 0.54 & NS \\
Firing onset delay $^{d}$ & 2.2 & 2.3 & $1.6^{*}$ & $p<0.05$
\end{tabular}

${ }^{a} \log 10$ of infield/outfield firing rate ratio, e.g., a score of 2.0 reflects a 100:1 spatial selectivity.

${ }^{b}$ Probability of firing when rat visits the place field.

${ }^{c} r$ for the cross-correlation between standard episodes.

${ }^{d}$ Number of trials completed before firing appears.

* Significantly different from young control, $p<0.05$, Duncan's test.

together with a rotated place field, confirming that the new place field was indeed a new representation and not one that rotated with some axial shift (Fig. $3 B$ ). In the aged rats the majority of responses involved disappearance of the place field and relatively few cases involved rotation with enhancement or appearance of a new field (Fig. 8). By contrast, in the young rats, about half of the responses involved appearance of a new field. A between-cells comparison revealed a significant group difference in the distribution of these subcategories of new representations $\left(\chi^{2}=15.2\right.$; $p<0.01)$. The between-subjects comparison also showed a significant group difference in the proportions of new fields $\left[F_{(2,30)}=\right.$ $4.2 ; p=0.02]$. In the post hoc test, only memory-impaired aged rats differed from the young rats $(p<0.05)$.

Additional test conditions were presented in which the spatial configuration of either the distal or the local cues was topographically reorganized or "scrambled" (Fig. 6). In young rats, the
Firing Onset Latency

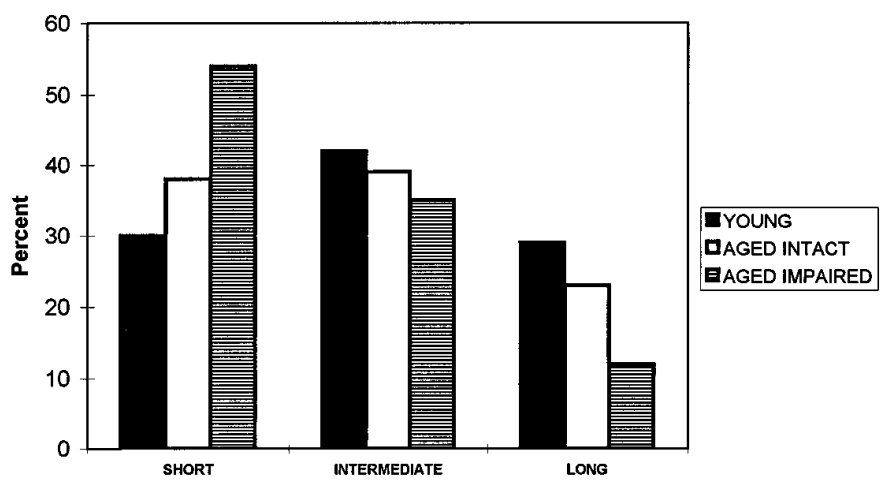

Figure 5. Firing onset latencies at the beginning of the second standard condition. Onset latencies are grouped into three categories: SHORT, firing begins during the first trial; INTERMEDIATE, firing begins during second or third trial; $L O N G$, firing begins during the 4th-16th trials. Memory-impaired aged rats have significantly more cells beginning to fire immediately and fewer cells with late firing onset.

largest proportion of the cells responded by developing new firing patterns when either the distal or the local cues were scrambled, indicating that the predominant spatial representation involves the configuration of both types of cues. In memory-impaired aged rats the response pattern was similar to that of young rats only when the distal cues were scrambled. Conversely, by contrast to young rats, firing patterns of the majority of cells in memoryimpaired aged rats did not change when the local cues were scrambled.

In the between-cells analysis, on the distal scramble condition the distribution of responses differed significantly among the three experimental groups $\left(\chi^{2}=17.3 ; p<0.01\right)$ and between the memory-impaired aged rats and the other two groups (memoryimpaired vs young, $p<0.05$; memory-impaired vs unimpaired, $p<0.01)$. On the local scramble condition responses differed among the three experimental groups $\left(\chi^{2}=31.0 ; p<0.00001\right)$ and between young and aged rats (young vs memory-impaired, $p<0.00001$; young vs unimpaired, $p<0.01$ ), but the two groups of aged rats did not differ. In a between-subjects analysis, the distribution of responses did not differ between the experimental groups on distal scramble conditions but did differ on the local scramble condition $\left[F_{(4,48)}=4.7 ; p<0.01\right]$. The one-way ANOVA revealed a significant group difference in the number of "no change" $\left[F_{(2,32)}=3.8 ; p=0.03\right]$ and "new representation" $\left[F_{(2,32)}=5.5 ; p=0.01\right]$ responses. Young rats differed from memory-impaired aged rats in both cases (Duncan's test, $p<$ $0.05)$. These findings confirm the disproportionate representation of distal cues associated with aging and memory impairment and show that hippocampal cells encoded the spatial configuration of the distal cues even in memory-impaired aged rats. Only when the configuration of distal spatial cues was disrupted did memoryimpaired aged rats use local or constant room cues to the same extent as young rats (Fig. $3 C$ ), indicating that aged rats can successfully use the local cues to guide behavior.

To determine whether hippocampal cells in aged rats were more likely to be controlled by a single cue rather than the overall configuration of cues, we also presented test conditions in which a particular distal or local cue was deleted. In young rats a surprisingly large proportion of cells developed a new firing pattern when a single distal or local cue was deleted (Fig. 6), indicating, contrary to previous characterizations of place cells 


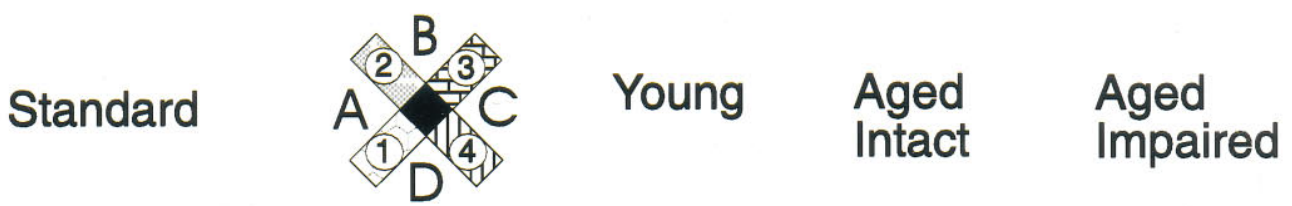

\section{Double Rotation}

\section{Distal Scramble}

\section{Local Scramble}

\section{Distal Removal}

Local
Removal
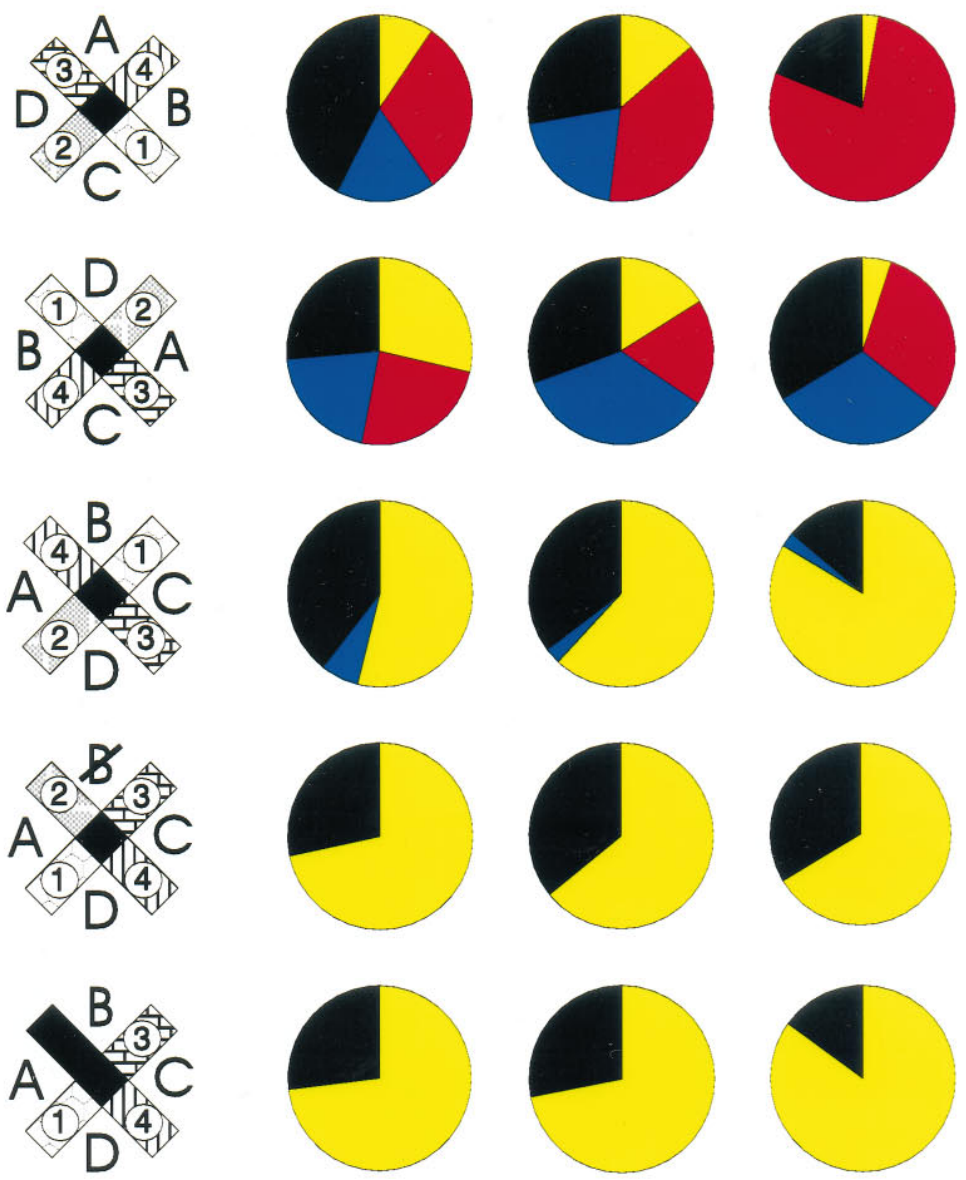

Figure 6. Changes in spatial firing patterns of hippocampal neurons during test conditions. For each type of manipulation the change in the hippocampal representation is quantified by the proportions of cells that responded in one of four different ways: no change in the spatial coding, rotation of the place field corresponding to the new distal cue positions, rotation of the place field corresponding to the new local cue positions, or one of several types of new spatial representation. The predominant proportion of cells in young rats responded to double rotation and local scramble by developing new representation, whereas the vast majority of cells in aged memory-impaired rats were following distal cues in both situations. The response pattern of aged memory-intact rats was intermediate but closer to that of young than aged memory-impaired rats. When distal cues were either rotated or scrambled a substantial minority of cells in the young and memory-intact aged rats had fields that maintained a fixed position with the constant room cues, whereas practically all cells in aged memory-impaired rats had changes in their place fields. Conversely, the groups did not differ in their responses to a single cue removal.

(O'Keefe and Conway 1978), that hippocampal spatial representations depend on single cues even in environments with many spatial cues. In aged rats, the same proportion of cells developed a new spatial representation when either a distal cue or a local cue was deleted, as did cells in young rats. In the between-cells analysis, responses did not differ significantly between young and aged rats on either the distal removal condition $\left(\chi^{2}=3.7\right)$ or the local removal condition $\left(\chi^{2}=5.2\right)$. Neither did between-subjects analysis yield any difference between the groups in either distal removal $\left[F_{(2,16)}=0.32\right]$ or local removal $\left[F_{(2,23)}=0.26\right]$ conditions.

\section{Plasticity of the spatial representation}

The pattern of hippocampal spatial representations changed over the course of repeated alternations of standard and test conditions in young and memory-intact but not in memory-impaired aged rats. In 


\section{A First Double Second Local Distal Standard rotation Standard scramble scramble
(2)
$10 \times 1$
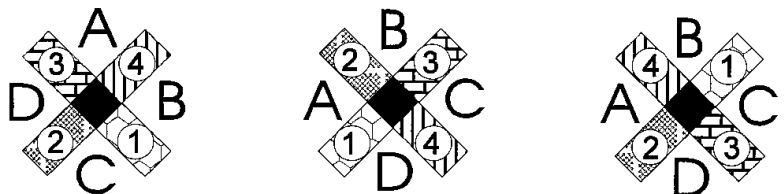 \\ $A+C$

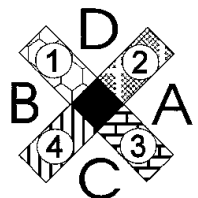

Raw firing rates
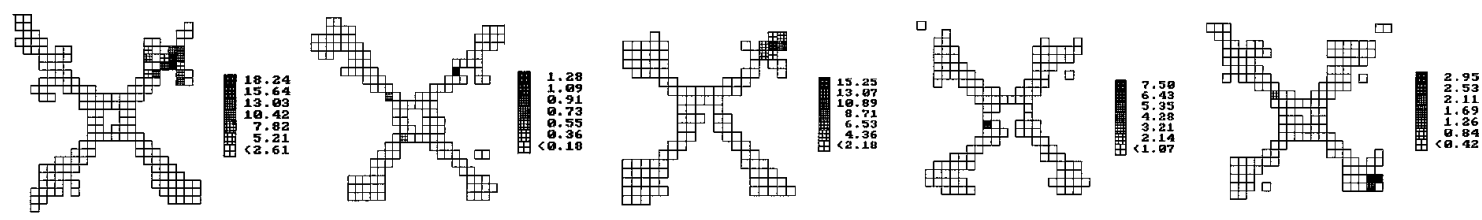

Place fields
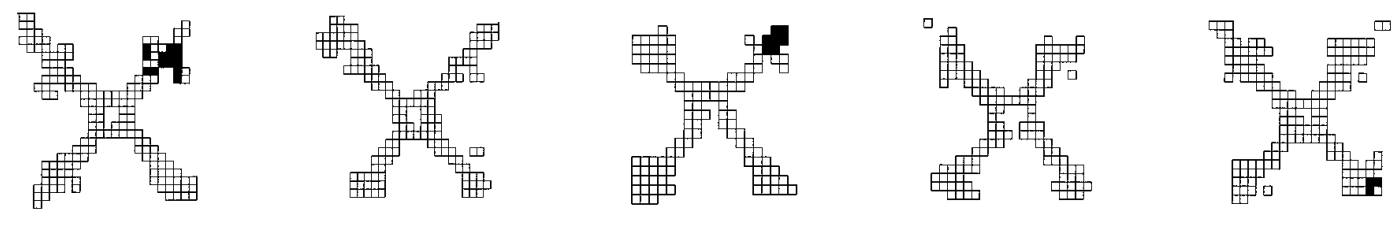

$A=14, \quad R=7.2$

$A=0, \quad R=0$

$A=7, \quad R=5.8$

$A=0, \quad R=0$

$A=3, \quad R=2.3$

$B$ First Standard

\section{Double}

Second

Local

Distal

Standard scramble

scramble
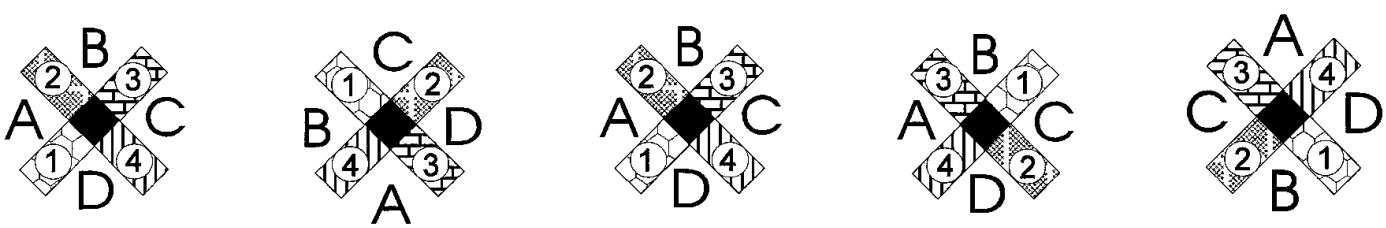

Raw firing rates
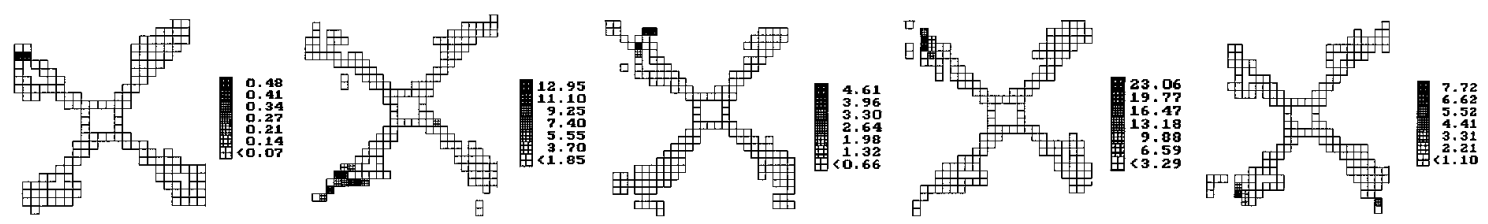

Place fields

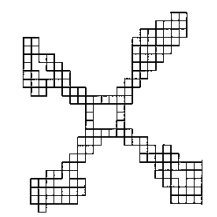

$A=0, \quad R=0$
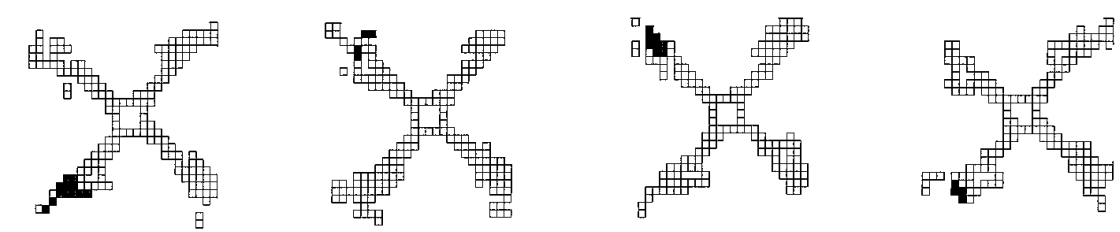

$A=4, \quad R=3.3$

$A=8, \quad R=7.7$

$A=4, \quad R=3.0$ 
First Standard
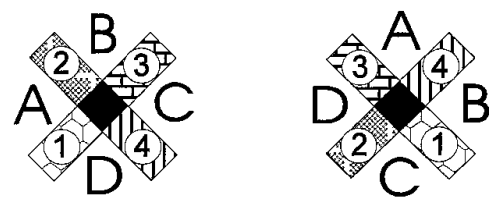
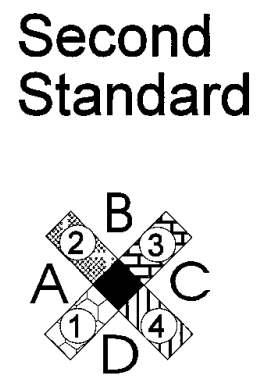
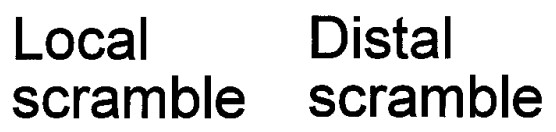

\section{Raw firing rates}
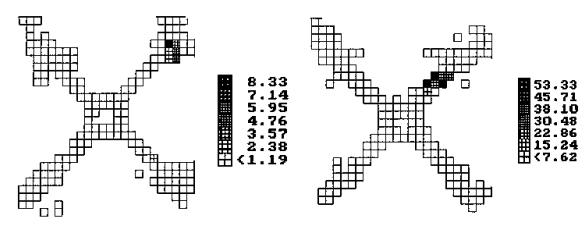

Place fields

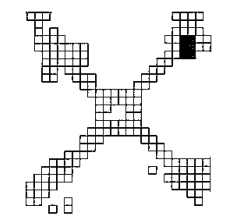

$A=6, \quad R=3.4$

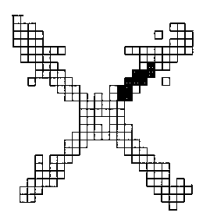

$A=11, \quad R=15.8$
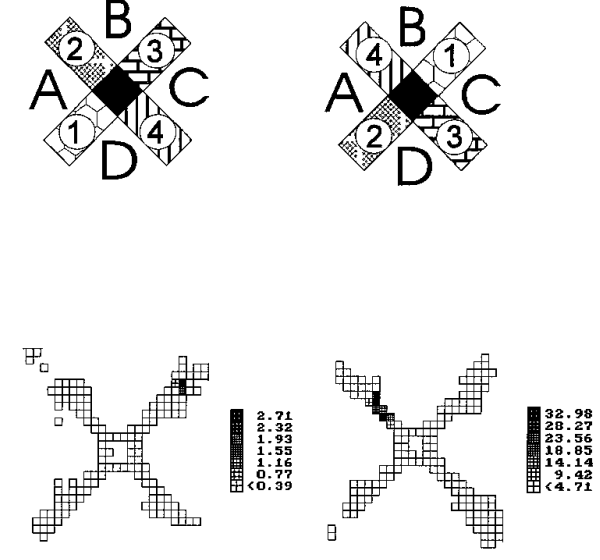

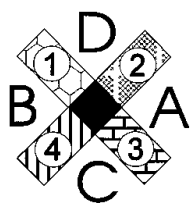

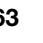



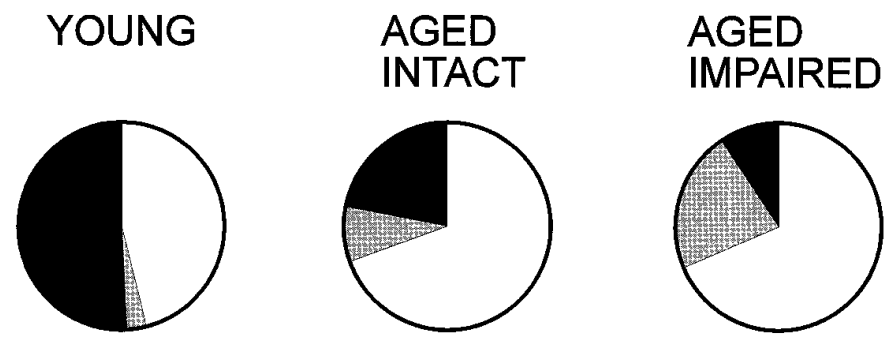

\section{$\square$ Disappearance}

\section{Rotation with enhancement}

\section{New field}

Figure 8. The response category new representation is divided into three different subcategories: (1) disappearance of the field, (2) rotation with enhancement, and (3) new field appears. There is a sharp decline in the proportion of new field responses with both age and memory impairment and, conversely, increases in rotation with enhancement and disappearance.

\section{Additional behavioral test for olfaction}

Finally, to test whether indifference of aged place cells to local cue scramble could be attributable to impaired olfaction in these rats, four of the aged rats were tested in a simple olfactory discrimination task (Zyzak et al., 1995). Two old memory-intact rats discriminated $95 \%$ correctly with undiluted odors, $80 \%$ correctly with 1:10 dilutions, and $85 \%$ correctly with 1:100 dilutions. Corresponding performances for two memory-impaired rats were 100 , 95 , and $85 \%$, respectively. The performances of old animals were essentially the same as those of a group of young rats from the same batch $(89,89$, and $90 \%$ correct, respectively). Thus it is highly unlikely that impaired olfaction made the undiluted odor cues on the maze less prominent for the aged rats than for their young counterparts.

\section{DISCUSSION}

The present study confirms the earlier reports that the hippocampal place fields of aged rats are similar in basic firing properties to those of young animals (Barnes et al., 1983; Mizumori et al.,
1996). Age-related alterations in the spatial specificity of CA1 and hilar (CA3c) place cells have been observed before, but the results of separate studies conflict. Barnes et al. (1983) found less specific and less reliable firing of CA1 complex spike cells in aged animals, whereas Mizumori et al. (1996) found that CA1 cells in aged rats had increased spatial and directional specificity, whereas hilar cells showed decreased spatial and directional coding. In the present study spatial selectivity, reliability, and directional specificity did not differ significantly between the groups and, to the extent that any trend was reflected in the group differences, place fields in the memory-impaired aged rats showed the greatest spatial specificity, reliability, and directionality. However, the current results show that place cells of aged rats tend to have multiple fields more often than do cells of young rats, although the number of place fields per complex spike cell did not correlate with spatial learning ability. In addition, contrary to one previous report (Mizumori et al., 1996), no differences in firing properties between CA1 and CA3 cells were observed in this study.

Although place fields of memory-impaired aged rats are similar to those of young rats in these quantitative aspects of their firing patterns, the present findings suggest that other qualities that reflect the underlying information processing change considerably with age and declining performance. We expected to find that place cells in young animals would be primarily under the control of distal cues, whereas those in aged rats would be primarily under the control of local cues, a distinction made in comparisons of place cell responses to environmental manipulations in intact young rats versus young rats with direct damage to hippocampal connections (Miller and Best, 1980; Shapiro et al., 1989). Thus we were surprised to observe that most cells in young rats were equally controlled by distal, local, and constant room cues, whereas most cells in memory-impaired aged rats responded selectively to distal cues. Indeed, the complex spike cells of memory-impaired aged rats could be characterized as "ideal" place cells in that they were almost completely under the control of distal cues, were little affected by removal of any single distal cue, and were disrupted when the relationships between distal cues were altered (O'Keefe and Conway, 1978).

The lack of control by local cues on place cell firing in aged animals cannot be explained simply by an inability to perceive the

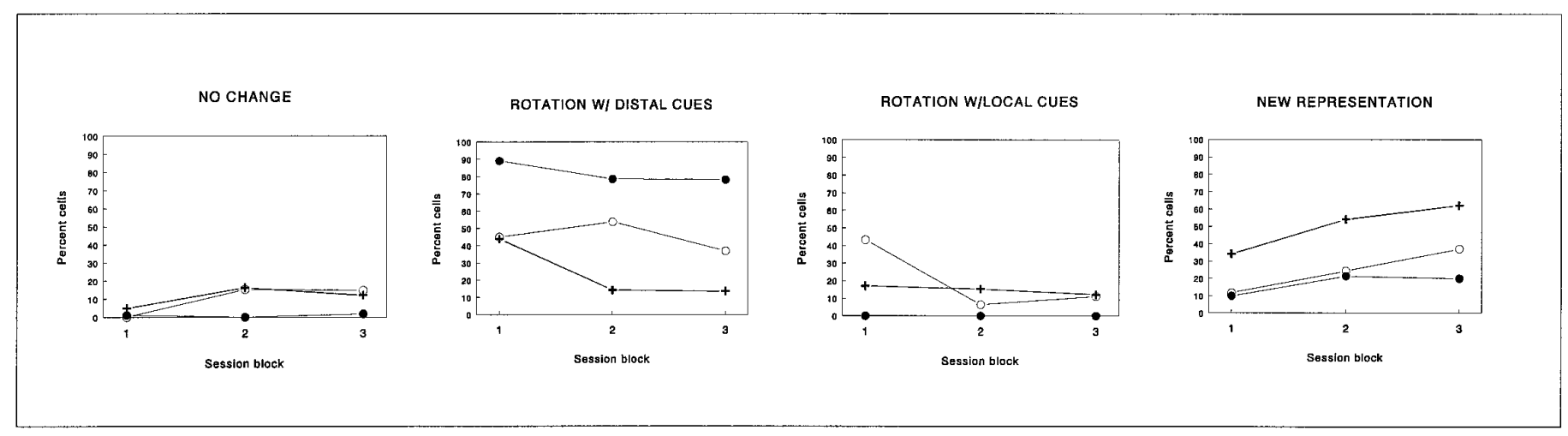

Figure 9. Changes in spatial representations over the course of repeated testing with standard and test conditions. Changes in the distribution of the four types of responses to double rotation (see Fig. 6) over the course of three consecutive blocks of four to six recording sessions each are shown. In young and aged memory-intact rats the proportion of cells that respond to cue manipulations by field rotations decreases toward the end of the experiment, whereas the proportion of cells that are controlled by constant room cues or develop new representation increases. In contrast, there were no significant differences in response types across session blocks in aged memory-impaired rats. 
local cues. When single local cues were removed, place fields were changed in about one-third of the cells in both young and aged rats. Moreover, when the relationships between distal cues were scrambled, place fields of memory-impaired aged rats often followed the local cues rather than a particular distal cue, although the influence of a single distal cue cannot completely be ruled out, because one distal cue always rotated with the local set. These results and earlier findings (Zyzak et al., 1995) indicate that the old animals have no difficulty in detecting and using local olfactory cues. Distal cues are certainly sufficient to solve spatial problems (Morris, 1984; O'Keefe and Speakman, 1987) and would provide information for guiding movements from any location in a large environment, and this would not be true of local cues perceived only in particular parts of the maze. Thus the representational strategy of aged rats can be characterized as a selective encoding of the most consistently available or predictive spatial cues. In young rats, the hippocampus encodes and integrates more information than "needed," including a broader range of cues than required for task solution, and this integration of a broad scope of cues is lacking in some aged animals.

Rats have been shown to use two different strategies for spatial navigation: coding of the relative positions of distal landmarks and path integration, that is, keeping track of the animal's position by integrating self-motion information (McNaughton et al., 1996). It has been suggested that the place fields in a new environment are primarily based on path integration, and the role of distal landmarks is to correct the gradual error that accumulates. After repeated exposure to the environment the place fields become more and more under the control of distal landmarks, which results in "focusing" of the place fields, that is, increasing their spatial selectivity (Austin et al., 1993; Wilson and McNaughton, 1993; McNaughton et al., 1996). The present finding of increased spatial selectivity standard conditions toward the end of the experiment in both young and aged rats suggests that this aspect of spatial processing is intact in aging. However, as demonstrated in our accompanying paper (Tanila et al., 1997), this focussing of place fields may take more time in aged memory-impaired rats than in memory-intact ones. Moreover, the present observation that place cells of memory-impaired aged rats began firing significantly earlier in the testing episode suggests that less processing of the relationships among the environmental cues may be done before the place cell fires in memory-impaired aged animals. Possibly the decreased processing time reflects the failure to encode more than the most prominent (distal) cues.

Although a subset of aged rats are impaired in spatial learning, they gradually improve across trials and eventually perform clearly above the chance level (Barnes, 1988; DeToledo-Morrell et al., 1988; Gage et al., 1988; Gallagher et al., 1995). The present findings suggest that this memory deficit is not attributable to the loss of hippocampal neurons that encode environmental cues but, rather, to the selective nature of the information stored and a diminished plasticity of the spatial representation. Previous studies of cognitive aging have focused on the loss of cells, synapses, synaptic plasticity, and other forms of anatomical or physiological compromise (Barnes, 1988; DeToledo-Morrell et al., 1988; Gage et al., 1988; Gallagher et al., 1995; Grady et al., 1995). The present findings suggest that age-associated memory loss may also be the consequence of a different form of neural representation that occurs with aging and not of a loss of neurons responsive to sensory cues, consistent with recent observations of no hippocampal cell loss in aging rats (Rasmussen et al., 1996), monkeys (Rapp and Gallagher, 1996), or humans (West, 1993).
At this point it remains speculative how the documented changes in hippocampal circuitry in aged rats result in altered neural representation of the environment. There is both anatomical (Geinisman and Bondareff, 1976) and physiological (Barnes and McNaughton, 1980) evidence that the dentate granule cells in aged rats receive up to one-third fewer afferents from the entorhinal cortex than in young rats. The role of the dentate gyrus in the hippocampal circuitry has been suggested to provide CA3 pyramidal cells with sparsely coded, distributed representation of the environment (Jung and McNaughton, 1993). With loss of afferent input this representation of all available environmental cues and their spatial relationships may be defective, which results in coding only for the most prominent cues, which was seen in our aged memory-impaired rats. With the intact CA3 recurrent collateral system enabling pattern completion (Rolls, 1990), the aged memory-impaired rats could still create a representation of the whole environment. In other words, they are seeing what they remember rather than remembering what they see. Another factor favoring pattern completion at the cost of processing new incoming information may be reduced cholinergic innervation of the hippocampus in aged rats (Gallagher et al., 1995). According to the hypothesis of Hasselmo and Schnell (1994), acetylcholine turns off pattern completion. Finally, altered neuronal plasticity mechanisms such as defective function of glutamatergic NMDA receptors reported in the aged rat hippocampus (Barnes et al., 1994) could have accounted for the lack of plasticity in the spatial representation over repeated changes in the environment. Future studies challenging the hippocampus with specific pharmacological agents or using appropriate mutant mice could eventually point out those changes in the aging hippocampus that lead to the observed change in the encoding of spatial information with age.

\section{REFERENCES}

Austin KB, White LH, Shapiro ML (1993) Short- and long-term effects of experience on hippocampal place fields. Soc Neurosci Abstr 19:797.

Bachevalier J, Landis LS, Walker LC, Brickson M, Mishkin M, Price DL, Cork LC (1991) Aged monkeys exhibit behavioral deficits indicative of widespread cerebral dysfunction. Neurobiol Aging 12:99-111.

Barnes CA (1979) Memory deficits associated with senescence: a neurophysiological and behavioral study in the rat. J Comp Physiol Psychol 93:74-104.

Barnes CA (1988) Aging and the physiology of spatial memory. Neurobiol Aging 9:563-568.

Barnes CA, McNaughton BL (1980) Physiological compensation for loss of afferent synapses in rat hippocampal granule cells during senescence. J Physiol (Lond) 309:473-485.

Barnes CA, Nadel L, Honib WK (1980) Spatial memory deficit in senescent rats. Can J Psychol 34:29-39.

Barnes CA, McNaughton BL, O'Keefe J (1983) Loss of place specificity in hippocampal complex spike cells of senescent rats. Neurobiol Aging 4:113-119.

Barnes CA, Green EJ, Baldwin J, Johnson WE (1987) Behavioral and neurophysiological examples of functional sparing in senescent rat. Can J Psychol 41:131-140.

Barnes CA, Treves A, Rao G, Shen J (1994) Electrophysiological markers of cognitive aging: region specificity and computational consequences. Semin Neurosci 6:359-367.

Craik FIM (1990) Changes in memory with normal aging: a functional view. In: Advandex in neurology, Vol 51, Alzheimer's disease (Wurtman RJ, ed), pp 201-205. New York: Raven.

DeToledo-Morrell L, Geinisman Y, Morrell F (1988) Age-dependent alterations in hippocampal synaptic plasticity: relation to memory disorders. Neurobiol Aging 9:581-590.

Eichenbaum H (1996) Is the rodent hippocampus just for "place"? Curr Opin Neurobiol 6:187-195.

Gage FH, Chen KS, Buzsaki G, Armstrong D (1988) Experimental approaches to age-related cognitive impairments. Neurobiol Aging 9:645-655. 
Gallagher M, Burwell RD, Burchinal M (1993) Severity of spatial learning impairment in aging: development of a learning index for performance in the Morris water maze. Behav Neurosci 107:618-626.

Gallagher M, Nagahara AH, Burwell RD (1995) Cognition and hippocampal systems in aging: Animal models. In: Brain and memory: modulation and mediation of neuroplasticity (McGaugh JL, Weinberger N, Lynch G, eds), pp 103-126. New York: Oxford UP.

Geinisman Y, Bondareff W (1976) Decrease in the number of synapses in the senescent brain: a quantitative electron microscopic analysis of the dentate gyrus molecular layer in the rat. Mech Ageing Dev 5:11-23.

Grady CL, McIntosh AR, Horwitz B, Maisog JM, Ungerleider LG, Mentis MJ, Pietrini P, Schapiro MB, Haxby JV (1995) Age-related reductions in human recognition memory due to impaired encoding. Science 269:218-221.

Hasselmo ME, Schnell E (1994) Laminar selectivity of the cholinergic suppression of synaptic transmission in rat hippocampal region CA1: computational modeling and brain slice physiology. J Neurosci 14:3898-3914.

Hetherington PA, Shapiro ML (1996) Hippocampal place fields are altered by the removal of single visual cues in a distant-dependent manner. Behav Neurosci 111:20-34.

Jung MW, McNaughton BL (1993) Spatial selectivity of unit activity in the hippocampal granular layer. Hippocampus 3:165-182.

Markowska AL, Stone WS, Ingram DK, Reynolds J, Gold PE, Conti LH, Pontecorvo MJ, Wenk GL, Olton DS (1989) Individual differences in aging: behavioral and neurobiological correlates. Neurobiol Aging 10:31-43.

McNaughton BL, Barnes CA, Meltzer J, Sutherland RJ (1989) Hippocampal granule cells are necessary for normal spatial learning byt not for spatially selective pyramidal cell discharge. Exp Brain Res 76:485-496.

McNaughton BL, Barnes CA, Gerrard JL, Gothard K, Jung MW, Knierim JJ, Kudrimoti H, Qin Y, Skaggs WE, Suster M, Weaver KL (1996) Deciprering the hippocampal polyglot: the hippocampus as a path integration system. J Exp Biol 199:173-185.

M'Harzi M, Jarrard LE (1992) Strategy selection in a task with spatial and nonspatial components: effects of fimbria-fornix lesions in rats. Behav Neural Biol 58:171-179.

Miller VM, Best PJ (1980) Spatial correlates of hippocampal unit activity are altered by lesions of the fornix and entorhinal cortex. Brain Res 194:311-323.

Mizumori SJY, Lavoie AM, Kalyani A (1996) Redistribution of spatial representation in the hippocampus of aged rats performing a spatial memory task. Behav Neurosci 110:1006-1016.

Morris R (1984) Developments of a water-maze procedure for studying spatial learning in the rat. J Neurosci Methods 11:47-60.
Morris RG, Garrud P, Rawlins JN, O'Keefe J (1982) Place navigation impaired in rats with hippocampal lesions. Nature 297:681-683.

Muller RU, Kubie JL (1987) The effects of changes in the environment on the spatial firing of hippocampal complex-spike cells. J Neurosci 7:1951-1968.

O'Keefe J, Conway DH (1978) Hippocampal place units in the freely moving rat: why they fire where they fire. Exp Brain Res 31:573-590.

O'Keefe J, Nadel L (1978) The hippocampus as a cognitive map. Oxford: Oxford UP.

O'Keefe J, Speakman A (1987) Single unit activity in the rat hippocampus during a spatial memory task. Exp Brain Res 68:1-27.

Ranck JB (1973) Studies on single neurons in dorsal hippocampal formation and septum in unrestrained rats. Exp Neurol 40:461-531.

Rapp PR, Amaral DG (1992) Individual differences in the cognitive and neurobiological consequences of normal aging. Trends Neurosci 15:340-344.

Rapp PR, Gallagher M (1996) Preserved neuron number in the hippocampus of aged rats with spatial learning deficits. Proc Natl Acad Sci USA 93:9926-9930.

Rapp PR, Heindel WC (1994) Memory systems in normal and pathological aging. Curr Opin Neurol 7:294-298.

Rasmussen T, Schliemann T, Sörensen JC, Zimmer J, West MJ (1996) Memory impaired aged rats: no loss of principal hippocampal and subicular neurons. Neurobiol Aging 17:143-147.

Rolls ET (1990) Functions of the primate hippocampus in spatial processing and memory. In: Neurobiology of comparative cognition (Kesner RP, Olton DS, eds), pp 339-362. Hillsdale NJ: Lawrence Erlbaum Associates.

Shapiro ML, Simon DK, Olton DS, Gage FH, Nilsson O, Björklund A (1989) Intrahippocampal grafts of fetal basal forebrain tissue alter place fields in the hippocampus of rats with fimbria-fornix lesions. Neuroscience 32:1-18.

Shapiro ML, Tanila H, Eichenbaum H (1995) Hippocampal neurons encode both local and distal stimuli in rats exploring a cue-controlled environment. Soc Neurosci Abstr 21:943.

Tanila H, Sipilä P, Shapiro M, Eichenbaum H (1997) Brain aging: impaired coding of novel environmental cues. J Neurosci 17:5167-5174.

Young BJ, Fox GD, Eichenbaum H (1994) Correlates of hippocampal complex-spike cell activity in rats performing radial maze task. J Neurosci 14:6553-6563.

West MJ (1993) Regionally specific loss of neurons in the aging human hippocampus. Neurobiol Aging 14:287-293.

Wilson MA, McNaughton BL (1993) Dynamics of the hippocampal ensemble code for space. Science 261:1055-1058.

Zyzak DR, Otto T, Eichenbaum H, Gallagher M (1995) Cognitive decline associated with normal aging in rats: a neuropsychological approach. Learn Mem 2:1-16. 